\title{
Peutz-Jeghers syndrome: a systematic review and recommendations for management
}

\author{
A D Beggs, ${ }^{1}$ A R Latchford, ${ }^{2}$ H F A Vasen, ${ }^{3}$ G Moslein, ${ }^{4}$ A Alonso,${ }^{5}$ S Aretz, ${ }^{6}$ \\ L Bertario, ${ }^{7}$ I Blanco, ${ }^{8} \mathrm{~S}$ Bülow, ${ }^{9} \mathrm{~J}$ Burn, ${ }^{10} \mathrm{G}$ Capella, ${ }^{11} \mathrm{C}$ Colas, ${ }^{12}$ W Friedl, ${ }^{6}$ \\ $\mathrm{P}$ Møller, ${ }^{13} \mathrm{~F} \mathrm{~J} \mathrm{Hes},{ }^{14} \mathrm{H}$ Järvinen, ${ }^{15} \mathrm{~J}-\mathrm{P}$ Mecklin, ${ }^{16} \mathrm{~F} \mathrm{M}$ Nagengast, ${ }^{17} \mathrm{Y} \mathrm{Parc}^{18}$ \\ R K S Phillips, ${ }^{19}$ W Hyer, ${ }^{19}$ M Ponz de Leon, ${ }^{20}$ L Renkonen-Sinisalo, ${ }^{15} \mathrm{~J}$ R Sampson, ${ }^{21}$ \\ A Stormorken, ${ }^{22}$ S Tejpar, ${ }^{23}$ H J W Thomas, ${ }^{24} \mathrm{~J} \mathrm{~T} \mathrm{Wijnen,}{ }^{14}$ S K Clark, ${ }^{19}$ \\ S V Hodgson ${ }^{1}$
}

For numbered affiliations see end of article.

\section{Correspondence to}

Professor Shirley Hodgson, Department of Clinical Genetics, St Georges, University of London, Cranmer Terrace, London SW17 ORE, UK shodgson@sgul.ac.uk

Revised 11 December 2009 Accepted 16 December 2009

\section{ABSTRACT}

Peutz-Jeghers syndrome (PJS, MIM175200) is an autosomal dominant condition defined by the development of characteristic polyps throughout the gastrointestinal tract and mucocutaneous pigmentation. The majority of patients that meet the clinical diagnostic criteria have a causative mutation in the STK11 gene, which is located at 19p13.3. The cancer risks in this condition are substantial, particularly for breast and gastrointestinal cancer, although ascertainment and publication bias may have led to overestimates in some publications. Current surveillance protocols are controversial and not evidence-based, due to the relative rarity of the condition. Initially, endoscopies are more likely to be done to detect polyps that may be a risk for future intussusception or obstruction rather than cancers, but surveillance for the various cancers for which these patients are susceptible is an important part of their later management.

This review assesses the current literature on the clinical features and management of the condition, genotype-phenotype studies, and suggested guidelines for surveillance and management of individuals with PJS. The proposed guidelines contained in this article have been produced as a consensus statement on behalf of a group of European experts who met in Mallorca in 2007 and who have produced guidelines on the clinical management of Lynch syndrome and familial adenomatous polyposis.

\section{INTRODUCTION}

Peutz-Jeghers syndrome (PJS) is an inherited polyposis syndrome in which multiple characteristic polyps occur in the gastrointestinal tract, associated with mucocutaneous pigmentation, especially of the vermilion border of the lips. It is inherited in an autosomal dominant manner and is caused by a germline mutation in the STK11 (LKB1) gene. The proposed guidelines contained in this article have been produced as a consensus statement on behalf of a group of European experts who met in Mallorca in 2007 and who have produced guidelines on the clinical management of Lynch syndrome ${ }^{1}$ and familial adenomatous polyposis. ${ }^{2}$

PJS was initially documented by an English physician $^{3}$ who described twin sisters with oral pigmentation, who were subsequently illustrated by the surgeon J Hutchinson. ${ }^{4}$ One of the twins died of an intussusception at age 20 years, and the other of breast cancer at 52 years.

The eponym Peutz-Jeghers syndrome was originally put forward in 1954 by Bruwer et al ${ }^{5}$ who based the name on the work of Peutz, ${ }^{6}$ who described a family with autosomal dominant inheritance of gastrointestinal polyposis and pigmented mucous membranes, and Jeghers ${ }^{7}$ who defined the coexistence of mucocutaneous pigmentation and gastrointestinal polyposis as a distinct clinical entity.

The incidence of this condition is estimated to be between 1 in 50000 to 1 in 200000 live births. ${ }^{9}$

\section{CLINICAL FEATURES}

Mucocutaneous pigmented lesions are seen in around $95 \%$ of patients and may be the first clue to an individual having PJS. Lesions tend to arise in infancy, occurring around the mouth, nostrils, perianal area, fingers and toes, and the dorsal and volar aspects of hands and feet. They may fade after puberty but tend to persist in the buccal mucosa. The histology of the pigmented macules is increased melanin in basal cells, possibly due to an inflammatory block to melanin migration from melanocyte to keratinocyte. Lip freckling is not unique to PJS and the differential diagnosis includes Carney complex, a syndrome characterised by spotty skin pigmentation and lentigines, most commonly on the face, especially on the lips, eyelids, conjunctiva and oral mucosa. ${ }^{10}$

The polyps seen in PJS have characteristic histological features, with a frond-like elongated epithelial component and cystic gland dilatation extending into the sub-mucosa or muscularis propria, and arborising smooth muscle extending into polyp fronds (in contrast to juvenile polyps, which have a lamina propria lacking smooth muscle ${ }^{11}$ ). These polyps are usually referred to as hamartomas, but controversy surrounds their origin. It has been suggested that the process underlying their development may be mechanical, or that they may be a result of stromal neoplasia. ${ }^{12}$ Small bowel polyps may display the phenomenon of 'pseudoinvasion', which may be mistaken for invasive carcinoma. ${ }^{13}$ The lack of cytological atypia among other features can distinguish between true and pseudo invasion.

Polyps are found throughout the gastrointestinal tract but most are in the small bowel $(60-90 \%)^{14}$ and colon (50-64\%). They may also be found at 
extra-intestinal sites such as the gallbladder, bronchi, bladder and ureter. $^{15}$ Gastrointestinal polyps may cause gastrointestinal bleeding, anaemia and abdominal pain due to intussusception, obstruction or infarction. Polyp-related symptoms usually arise in childhood and are seen by the age of 10 years in 33\% and by 20 years in $50 \%$.

In a single individual, a clinical diagnosis of PJS may be made when any ONE of the following is present ${ }^{16}{ }^{17}$ :

1. Two or more histologically confirmed PJ polyps

2. Any number of PJ polyps detected in one individual who has a family history of PJS in close relative(s)

3. Characteristic mucocutaneous pigmentation in an individual who has a family history of PJS in close relative(s)

4. Any number of PJ polyps in an individual who also has characteristic mucocutaneous pigmentation.

A study by Aretz et $a l^{17}$ correlated the diagnostic criteria for PJS with STK11 mutation detection rates. Of the patients who met the criteria for PJS, over $94 \%$ had a mutation detected $(64 \%$ point mutation, $30 \%$ deletions).

\section{MOLECULAR GENETICS OF PJS}

Initial linkage analysis localised the affected gene to chromosome 19p13.3. ${ }^{18}{ }^{19}$ Further studies identified a gene encoding a serine-threonine kinase, STK11 (LKB1). ${ }^{2021}$ Hemminki et al ${ }^{20}$ cloned the gene and demonstrated mutations in the STK11 gene in 11/12 (90\%) PJS cases using direct sequencing of DNA and mRNA. Recent studies which have searched for germline mutations by both direct sequencing and also multiplex ligation dependent probe amplification (MLPA) demonstrate a detection rate of germline mutations between $80 \%$ and $94 \%{ }^{17} 2223$

Loss of heterozygosity at $19 \mathrm{p} 13.3$ seen in PJS polyps and malignancy suggests that STK11 acts as a tumour suppressor gene. The gene is more than $23 \mathrm{~kb}$ in length, and extends over nine exons, encoding a 433 amino acid protein.

The function of STK11 is complex and still being clarified. ${ }^{24}$ This serine-threonine kinase is expressed ubiquitously in adult and fetal tissue. In brief, STK11 has been found to regulate cellular proliferation via G1 cell-cycle arrest, WAF1 (a cyclindependent kinase inhibitor) signalling ${ }^{25} 26$ and p53 mediated apoptosis. ${ }^{27}$ It has an important role in cell polarity ${ }^{28}$ and regulates the Wnt signalling pathway. ${ }^{29}$ It is also involved in cell metabolism and energy homeostasis. ${ }^{30}$ It is an upstream regulator of AMP activated protein kinase (AMPK), thereby regulating the TSC pathway and acting as a negative regulator of the mammalian target of rapamycin (mTOR) pathway. ${ }^{31}$ The mTOR pathway is particularly important as it is a final common pathway that is also dysregulated by other hamartomatous polyposis syndromes caused by germline PTEN, BMPR $1 A$ and SMAD4 mutations.

Over-expression of COX-2 has been noted in PJS polyps and cancers, ${ }^{32}$ and may present a therapeutic target for modulation of polyp development.

A single family has shown linkage to $19 q 13.4^{19}$ and some evidence of linkage to $6 \mathrm{p} 11$-cen has also been demonstrated. ${ }^{33}$ In addition, linkage studies of PJS families looking for a second PJS locus $^{34} 35$ suggested that in some the $19 \mathrm{p} 13.3$ locus was not involved in PJS. This has raised the possibility of genetic heterogeneity. A recent study ${ }^{36}$ examined the role of mutations in the MYH11 gene in 25 STK11 mutation negative patients with the PJS phenotype. One patient had a mutation (c.5798_5799insC) in the MYH11 gene, although this mutation was also found in apparently unaffected relative. Although genetic heterogeneity has been questioned, no clear second causative gene has been found for PJS cases without detectable
STK11 mutation. It is likely that with continued improvements in genetic testing that mutation detection rates will improve further, making genetic heterogeneity even less likely.

\section{Genotype-phenotype correlation}

A genotype-phenotype correlation has been sought in PJS. Amos et $a l^{37}$ suggested individuals with missense mutations had a later onset of symptoms than individuals with other mutations in STK11. Schumacher et al ${ }^{38}$ suggested that in-frame mutations in domains encoding protein and ATP binding and catalysis (I-VIA) were rarely associated with cancer, missense mutations in the $\mathrm{C}$ terminus and in the part of the gene encoding protein domains for substrate recognition (VIB-VIII) were more associated with malignancies, and patients with breast carcinomas had predominantly truncating mutations. Mehenni et $a l^{39}$ studied 49 PJS families with defined mutations, and found 32 cancers. They suggested that there was a higher risk of cancer in cases with mutations in exon 6 of the STK11 gene. These studies, however, are small and it is difficult to draw firm conclusions from them. Most studies have been carried out on western European populations but a study of LatinAmerican PJS patients ${ }^{40}$ demonstrated mutations in exon 2 (c.350_351insT) and exon 6 (c.811_813delAG) of the STK11 gene.

In a larger series 240 PJS patients with STK11 mutations were analysed. No difference was seen between individuals with missense and truncating mutations, nor between familial and sporadic cases although it was suggested that there was a higher risk of cancer in individuals with mutations in exon 3 of the gene. Hearle et $a^{41}$ continued this study, analysing a total of 419 PJS patients, 297 with documented mutations. They found that the type and site of mutation did not influence cancer risk.

In conclusion, no clear genotype-phenotype correlation has been demonstrated in PJS, and no clear differences found between cases with STK11 mutation and in those in whom no mutation has been detected.

\section{CANCER RISK}

How cancer arises in PJS and the role of the PJS polyp in cancer development remain controversial. It has been proposed that a unique hamartoma-adenoma-carcinoma pathway ${ }^{42}$ exists. This hypothesis is supported by the finding of adenomatous foci within PJS polyps and also by the description of cancer arising within PJS polyps. ${ }^{43}$ Others have proposed that the PJS polyps have no malignant potential. Malignant transformation within a PJS polyp is only seen as a rare event supporting this hypothesis. ${ }^{44}$ In addition PJS polyps have been shown to be polyclonal (and therefore unlikely to have malignant potential) and it is suggested that the 'PJS polyp' may actually represent a form of abnormal mucosal prolapse, ${ }^{44}$ caused by changes in cellular polarity induced by mutation in the STK11 gene, rather than a true hamartoma. If PJS polyps have no malignant potential it would imply that cancer arises on a background of mucosal instability, presumably through conventional neoplastic pathways. Whether this pathway is accelerated is an intriguing question which has yet to be answered. Certainly the fact that only one of the 17 colorectal cancers seen in the largest series $^{41}$ was detected at surveillance raises the possibility of an accelerated pathway (provided that patients were under surveillance and compliance was adequate). Further research in this area is required to clarify these issues.

Based on epidemiological and molecular genetic studies, ${ }^{45}$ it is now widely accepted that there is an increased risk of many cancers in PJS. Multiple single cohort studies have been carried 
out by individual groups ${ }^{14} 38$ 46-52 which make up the bulk of the literature. It is difficult to come to any firm conclusions from these relatively small studies, which are likely to be subject to both ascertainment and publication bias, thereby potentially inflating the cancer risk in PJS. A meta-analysis has been performed by Giardiello et al, assessing 210 patients from six studies. ${ }^{53}$ A study by Lim et a ${ }^{54}$ was subsequently continued by Hearle et $a l^{41}$ to produce a cohort of 419 patients with PJS. These studies by Giardiello and Hearle offer the most comprehensive data for cancer risk and their main findings are summarised in tables 1 and 2 .

Hearle et $a l^{41}$ examined the incidence of cancer in 419 individuals with Peutz-Jeghers syndrome, 297 of which had documented STK11 mutations. Ninety-six (23\%) developed cancer, the risks of which stratified by age are shown in table 1. Giardiello et al ${ }^{53}$ reviewed 210 PJS cases from six publications: the relative risks of cancer of different sites are shown in table 2. From these studies it can be seen that luminal gastrointestinal cancers and breast cancer are the most common cancers, followed by pancreatic cancer. It is striking in the Hearle study how risk increases rapidly after the age of 50 for all cancers, a fact not taken into consideration in most current surveillance protocols.

Mehenni et al $l^{55}$ recently examined the survival of 149 patients (76 male, 73 female) all of whom had a documented STK11 mutation (table 3 ). This study differs from those above in that only one case of breast cancer was observed. The reason for this discrepancy is not clear. Otherwise the predominance of luminal gastrointestinal cancer (especially colorectal) and the rapid increase in cancer risk after the age of 50 years are confirmed.

The observation of a rare sex cord tumour in PJS is important. Young et al $^{56}$ carried out a review of 74 sex cord ovarian tumours with annular tubules (SCTAT), of stromal origin. Of these, 27 were in individuals with PJS, and all were multifocal, bilateral, very small, benign and calcified. They could develop in young children, the youngest diagnosed at 4 years of age. Twelve affected individuals had hyper-oestrogen syndrome; four had adenoma malignum of the cervix of which two were fatal, diagnosed at 23 years and 36 years of age.

Song et $a l^{57}$ described the case of a 41-year-old woman with PJS who had multiple genital tract tumours and breast cancer; their literature review found that $36 \%$ patients with SCTAT have PJS, and SCTAT is usually benign and multifocal. Bilateral malignant ovarian sex cord tumour was described in a 47-yearold woman with PJS presenting with an abnormal cervical smear $^{58}$ and it was suggested that the hyper-oestrogenism caused by sex cord tumours could induce cervical adenoma malignum. This has a poor prognosis in general; of 10 cases reviewed by Srivatsa et al, ${ }^{59}$ eight died, only one survived longer than 5 years. One case of gonadoblastoma was described in a 34year-old PJS patient. ${ }^{60}$ Large-cell calcifying Sertoli cell tumours of the testis can also develop, usually in pre-pubescent boys,
Table 2 Risk ratios, frequencies and ages of onset of Peutz-Jeghers syndrome cancers by site (from Giardiello et $a l^{53}$

\begin{tabular}{lccll}
\hline Site & Risk ratio (95\% Cl) & Frequency (\%) & $\begin{array}{l}\text { Mean age } \\
\text { (years) }\end{array}$ & $\begin{array}{l}\text { Age range } \\
\text { (years) }\end{array}$ \\
\hline Oesophagus & $57(2.5$ to 557$)$ & 0.5 & 67 & \\
Stomach & $213(96$ to 368$)$ & 29.0 & 30.1 & $10-61$ \\
Small bowel & $520(220$ to 1306$)$ & 13 & 41.7 & $21-84$ \\
Colon & $84(47$ to 137$)$ & 39 & 45.8 & $27-71$ \\
Pancreas & $132(44$ to 261$)$ & 36 & 40.8 & $16-60$ \\
Lung & $17(5.4$ to 39$)$ & 15 & & \\
Testis & $4.5(0.12$ to 25$)$ & 9 & 8.6 & $3-20$ \\
Breast & $15.2(7.6$ to 27$)$ & 54 & 37.0 & $9-48$ \\
Uterus & $16(1.9$ to 56$)$ & 9 & & \\
Ovary & $27(7.3$ to 68$)$ & 21 & 28.0 & $4-57$ \\
Cervix & $1.5(0.31$ to 4.4$)$ & 10 & 34.3 & $23-54$ \\
\hline
\end{tabular}

leading to gynaecomastia because of hormonal imbalance caused by the neoplasm. ${ }^{61}$

Dozois et al ${ }^{62}$ reviewed 115 reported cases of PJS in females from the literature. Of these 16/115 had ovarian tumours diagnosed at ages 4.5 to 60 years. There were five granulosa cell tumours, five cystadenomas, four non-neoplastic cysts, one Brenner tumour, one dysgerminoma, and two with undetermined diagnoses.

Von Herbay ${ }^{63}$ reported a case of bronchoalveolar cancer of mucinous type in a 22-year-old male with PJS, hypothesising that it may represent a PJS associated cancer.

\section{CLINICAL MANAGEMENT \\ Surveillance}

Surveillance protocols in PJS have two main purposes. One is to detect sizeable gastroenterological polyps which could cause intussusception/obstruction or bleeding/anaemia. The other is the detection of cancer at an early stage. The indication for screening is therefore age dependent: polyp-related complications may arise in childhood, whereas the cancer risk largely pertains to the adult population.

Although most authorities agree that surveillance of some sort is warranted in patients with PJS, there is no consensus as to what organs should be monitored, with what frequency and when to start.

In order to carry out a comprehensive review of the literature a systematic review of the screening evidence was carried out.

\section{SYSTEMATIC REVIEW Method}

A systematic review of the available literature was carried out using the Ovid Medline 1950 to current; the Ovid EMBASE 1980 to current; Ovid OLDMEDLINE; Cochrane Database of Systematic Reviews and Pubmed.

Table 1 Cumulative cancer risk by site and age in Peutz-Jeghers syndrome patients (from Hearle et al ${ }^{41}$ )

\begin{tabular}{|c|c|c|c|c|c|c|}
\hline \multirow[b]{2}{*}{ Type of cancer } & \multicolumn{6}{|c|}{ Cancer risk by age $\%(95 \% \mathrm{CI})$} \\
\hline & 20 years & 30 years & 40 years & 50 years & 60 years & 70 years \\
\hline All cancers & $2(0.8$ to to 4$)$ & 5 (3 to 8$)$ & 17 (13 to 23$)$ & 31 (24 to 39$)$ & $60(50$ to 71$)$ & 85 (68 to 96$)$ \\
\hline Gastrointestinal & - & $1(0.4$ to 3$)$ & $9(5$ to 14$)$ & 15 (10 to 22$)$ & 33 (23 to 45$)$ & 57 (39 to 76$)$ \\
\hline Breast (female) & - & - & $8(4$ to 17$)$ & 13 (7 to 24$)$ & 31 (18 to 50$)$ & 45 (27 to 68$)$ \\
\hline Gynaecological & - & $1(0.4$ to 6$)$ & $3(0.9$ to 9$)$ & $8(4$ to 19$)$ & 18 (9 to 34$)$ & 18 (9 to 34$)$ \\
\hline Pancreas & - & - & $3(1$ to 7$)$ & $5(2$ to 10$)$ & 7 (3 to 16$)$ & 11 (5 to 24$)$ \\
\hline \multicolumn{7}{|l|}{ Lung } \\
\hline Male & - & - & $1(0.1$ to 6$)$ & $4(1$ to 11$)$ & 13 (6 to 28$)$ & 17 (8 to 36$)$ \\
\hline Female & - & - & $1(0.1$ to 6$)$ & - & - & - \\
\hline
\end{tabular}


Table 3 Frequency of cancer in Peutz-Jeghers syndrome (Mehenni et $a l^{55}$ )

\begin{tabular}{ll}
\hline Cancer site & Cancer frequency \\
\hline Gastro-oesophageal & $6 / 149$ \\
Small bowel & $4 / 149$ \\
Colorectal & $11 / 149$ \\
Pancreatic & - \\
Breast & $1 / 149$ \\
Gynaecological & $7 / 149$ \\
Lung & - \\
Male reproductive & - \\
Thyroid & - \\
Hepatobiliary & $1 / 149$ \\
Head and neck & $1 / 149$ \\
Other & - \\
\hline
\end{tabular}

Seperate search strategies were carried out with the MESH search term 'Peutz-Jeghers Syndrome' and 'screening'. Searches were combined with the AND operator.

All papers identified had their bibliography searched manually to identify further papers of interest. A separate literature search was carried out for therapeutic modalities using the MESH search terms 'Peutz-Jeghers Syndrome' and 'therapy'.

The strength of evidence was classified according to the north of England evidence-based guidelines development project ${ }^{64}$ (see table 4).

\section{Inclusion and exclusion criteria}

All articles discussing Peutz-Jeghers syndrome mentioning screening or surveillance were retrieved. For the therapy search, all articles discussing PJS mentioning any therapeutic aspect were retrieved. Acceptable article types retrieved were retrospective cohort studies, case reports, randomised controlled trials and case-control studies up to May 2009. Only English language articles were retrieved and all articles were reviewed independently for suitability (see figure 1).

\section{Results}

Screening

A total of 1254 papers were identified (Medline=73, Embase $=152$, Cochrane=0, OLDMedline=0, Pubmed=1029), of which 12 met the criteria. Manual examination of the bibliography of each paper found three additional papers that met the criteria, giving a total of 15 . Figure 1 shows the QUORUM flowchart for this search. Table 5 summarises the key recommendations of each of the papers retrieved.

\section{Therapy}

A total of 286 papers were identified (Medline $=26$, Embase $=9$, Cochrane=0, OLDMedline=0, Pubmed=251). All 286 met the criteria and were carried forward. Because of space constraints, these papers are not listed in this review.

\section{Surveillance recommendations}

Question: What is the role of surveillance endoscopic examination of the gastrointestinal tract?

One role for surveillance endoscopy is the detection of cancer. Giardiello et $a l^{53}$ found a range of age from 27 to 71 years for colorectal cancer diagnosis in PJS, with an overall risk of $39 \%$, the majority of which were in males. Hearle et $a l^{41}$ found that colorectal cancer was the most common luminal gastrointestinal cancer (17/40). The risk of colorectal cancer was 3\%, 5\%, 15\% and $39 \%$ at ages 40,50, 60 and 70 years, respectively. Although there was a male preponderance, this was not statistically significant. In this large series only one case of sigmoid cancer was detected during surveillance.

Upper gastrointestinal (GI) cancers are less common. Gastric cancer is far more common than oesophageal ${ }^{53}$ and the average age of stomach cancer diagnosis was 30 years. Although very rare, upper GI cancer has been reported during the first and second decades of life. ${ }^{53}$

The other indication for surveillance is the detection of large polyps allowing early therapy and the prevention of polyp related symptoms. There are sparse data regarding this. In a study from a single institution reporting outcomes from gastrointestinal surveillance, of 28 patients who had undergone one or more surveillance endoscopies by the age of 18 years, 17 were found to have developed significant gastroduodenal or colonic polyps. ${ }^{79}$ Thirty-nine colonic polyps and 20 gastroduodenal polyps larger than $1 \mathrm{~cm}$ were detected in these patients; the largest lesions were a $6 \mathrm{~cm}$ colonic polyp and an $8 \mathrm{~cm}$ gastric polyp.

The same series ${ }^{79}$ demonstrated that colonoscopic and upper GI tract surveillance is safe. During 786 surveillance examinations and over 1500 polypectomies, there were only two cases of perforation (both following resection of polyps larger than $2 \mathrm{~cm}$ ) and no post-polypectomy bleeding was observed.

Dunlop et al ${ }^{68}$ recommended screening intervals of every 3 years for upper and lower GI endoscopy, beginning at age 18 . Hemminki et al ${ }^{65}$ recommended screening start at age 18, with upper and lower GI endoscopy being performed at 2-5 year intervals. Giardiello et $a l^{9}$ recommended a baseline upper GI endoscopy at the age of 8 years and every $2-3$ years thereafter if polyps were detected. If no polyps are detected they recommend further surveillance upper GI endoscopy from the age of 18 years, with colonoscopic surveillance also starting at this age.

Some authors advocate not starting screening at all until age 18. We suggest starting at 8 years to pick up those with polyps at that stage to prevent problems in late childhood/early adolescence, which is when most obstructions occur. Data is lacking on the rate of polyp progression, but those with no polyps aged 8 years will still have follow-up, and be investigated if symptomatic/anaemic. There is a paucity of evidence to support recommendations here; however, we feel that this strikes a balance between preventing polyp complications and over-investigating children.

Table 4 Categories of evidence and grading of recommendations

\begin{tabular}{lll}
\hline Category of evidence & & Grading of recommendation \\
\hline Meta-analysis of randomised controlled trial & la & A \\
Randomised controlled trial & lb & A \\
Well designed controlled study without randomisation & Ila & B \\
Well designed quasi-experimental study & Ilb & B \\
Non-experimental descriptive study & III & B \\
Expert opinion & IV & C \\
\hline
\end{tabular}


Figure 1 QUORUM diagram for screening evidence review.

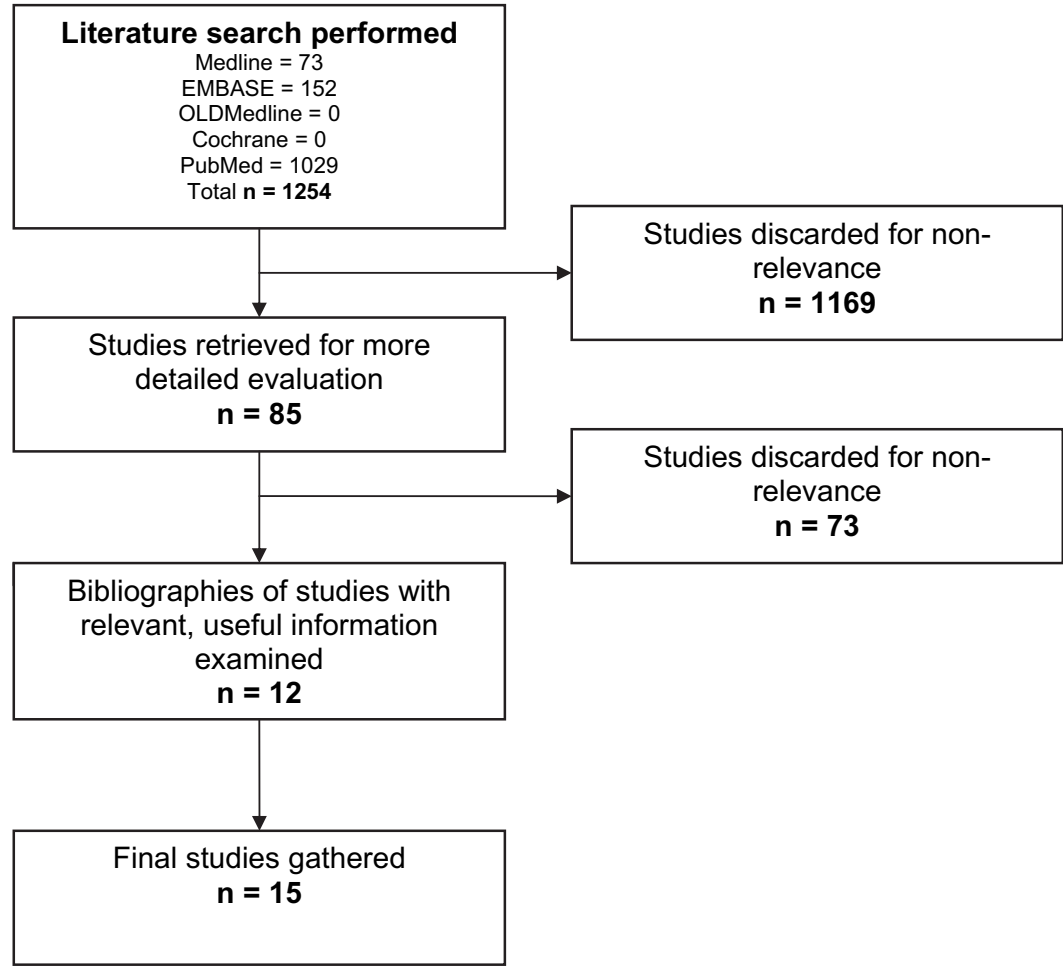

Conclusion: A baseline colonoscopy and upper GI endoscopy (OGD) is indicated at age 8 years. In those in whom significant polyps are detected these should be repeated every 3 years. In those in whom there are no significant polyps at baseline endoscopy, routine surveillance is repeated at age 18, or sooner should symptoms arise, and then three yearly. We recommend that after the age of 50 years the frequency is increased to every $1-2$ years due to the rapid increase in cancer risk at this age. There is, however, no evidence of benefit (Level of evidence: III, Grade of recommendation: C)

Question How and when should small bowel surveillance be performed in PJS?

Small bowel surveillance for polyps allows polypectomy before symptoms develop or obstruction occurs. A variety of investigations can be used.

Several studies ${ }^{80}$ have compared barium follow-through and capsule endoscopy. Two studies in adult patients found that video capsule endoscopy (VCE) has a greater sensitivity in detecting small bowel polyps. The study size was small in both studies. A prospective study has been performed comparing barium follow-through (BaFT) and VCE in paediatric patients with PJS. ${ }^{82}$ No significant difference was found in detection rates of polyps $>1 \mathrm{~cm}$ but VCE detected more polyps $<1 \mathrm{~cm}$ and also was much better tolerated. Many centres now use VCE, since it appears at least as accurate as barium follow through, is preferred by patients and reduces radiation exposure.

There are some early data on the use of magnetic resonance enterography (MRE) assessment of the small bowel in patients with PJS. Kurugoglu et $a l^{83}$ compared barium follow-through with ultrasound and MRE. They found that polyps were detected equally with contrast studies and MRE. Caspari et al ${ }^{84}$ compared VCE with MRE and observed that VCE was superior at detecting small polyps. Polyps of $15 \mathrm{~mm}$ and above were detected equally with both modalities and location of polyps and determination of their exact sizes was more accurate with MRE. Further studies to assess the utility of MRE are required.
There are no data to support the use of double-balloon enteroscopy as a method of small bowel surveillance in PJS. It is a prolonged, very invasive procedure and does not guarantee visualisation of the entire small bowel, especially in those who have undergone previous abdominal surgery. Although there are some reports of its use in PJS these are in the setting of therapy in patients with intussusception or prophylactically in patients who have had polyps detected by other means. ${ }^{79}$

The main indication for surveillance of the small bowel is the prevention of intussusception and the need for emergency laparotomy. There are limited data to guide when to start surveillance of the small bowel. A survey of adults with PJS ${ }^{70}$ found that by the age of 18 years, $23 / 34$ (68\%) of adults had undergone laparotomy, $70 \%$ of which were performed as an emergency. By the age of 10 years, $30 \%$ had required a laparotomy. In order to reduce the likelihood of developing intestinal obstruction, the study recommended that asymptomatic children start small bowel screening at the age of 8 years. A recent review of gastrointestinal surveillance from a single institution found that no patients enrolled on the programme required emergency surgery for obstruction or intussusception during 683 patient years follow-up. ${ }^{79}$

Conclusion: Small bowel screening using video capsule endoscopy (VCE) should be performed every 3 years if polyps are found at the initial examination, from age 8 years, or earlier if the patient is symptomatic. If few or no polyps are found at the initial examination, screening should commence again at the age of 18. Magnetic resonance enterography (MRE) and barium follow-through (BaFT) are reasonable alternatives in adult patients but BaFT is not favoured in children due to radiation exposure. (Level of evidence: III, Grade of recommendation: $\mathrm{B}$ )

Question: What is the best method of breast cancer surveillance in PJS?

The earliest documented case of breast cancer in PJS is 19 years, and clearly the breast cancer risk (cumulative risk 


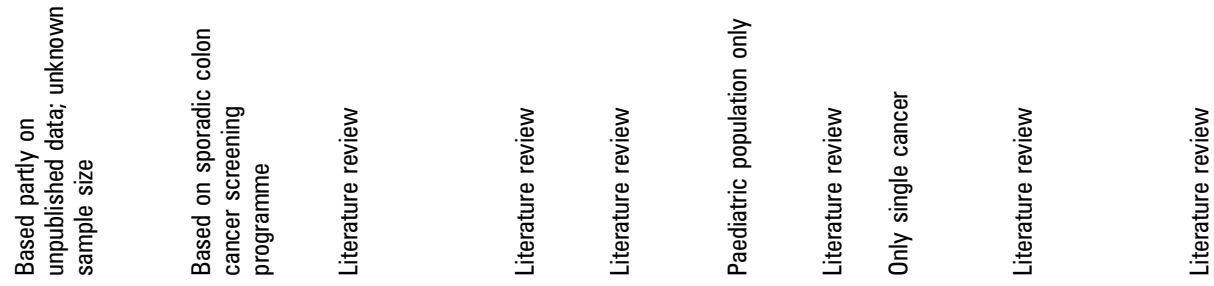
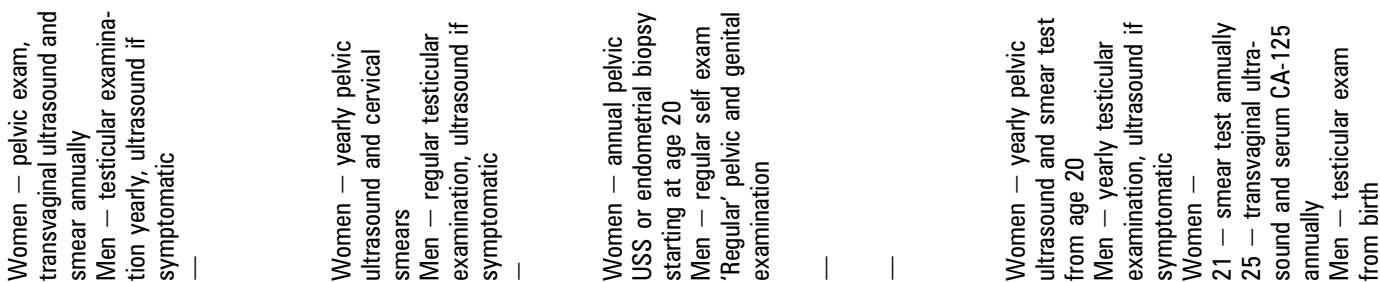

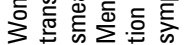
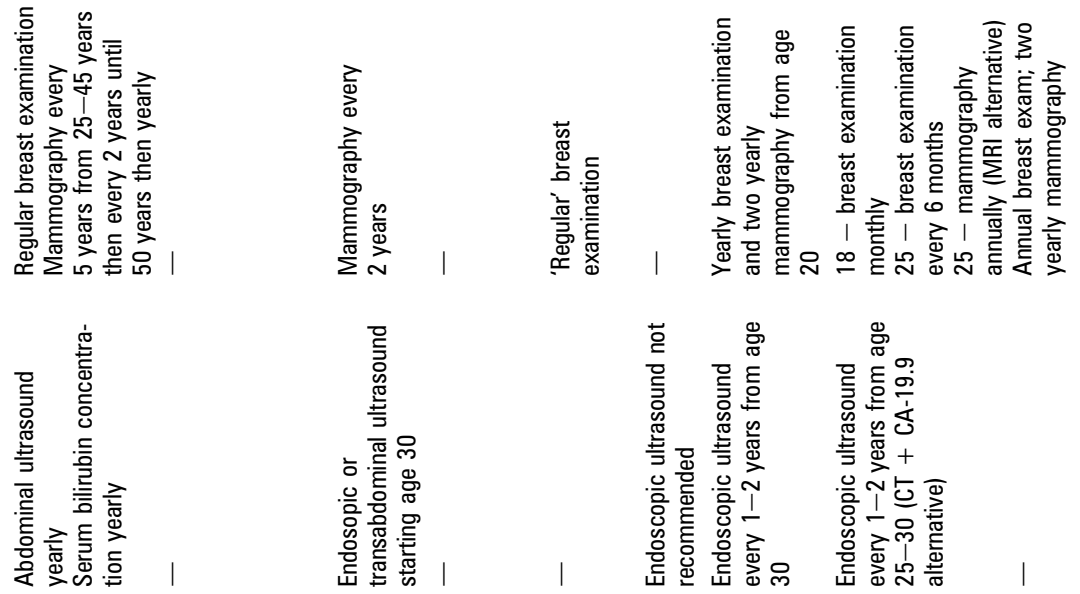

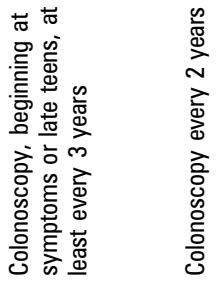
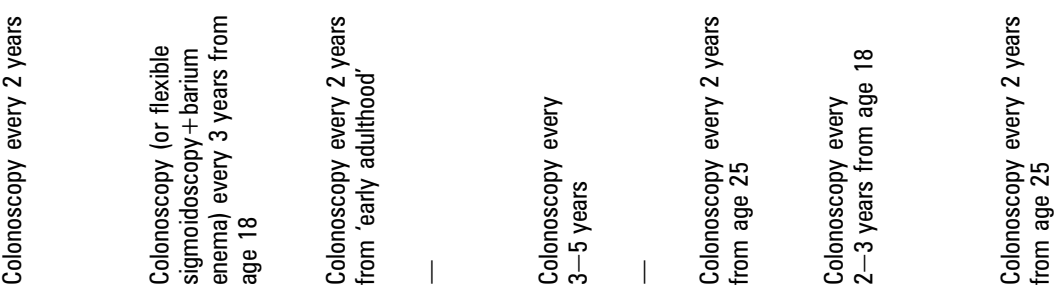

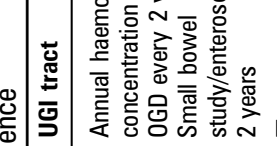
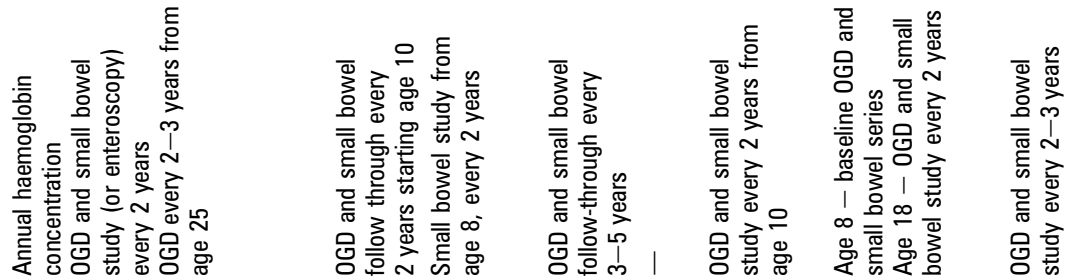

这的
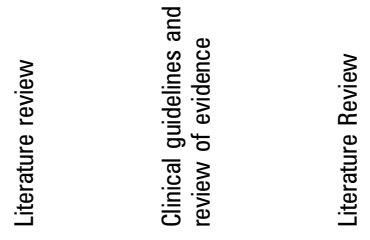

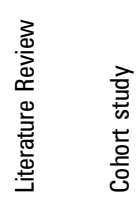

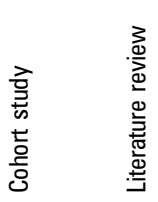

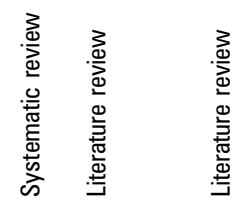

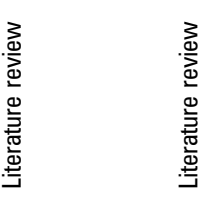

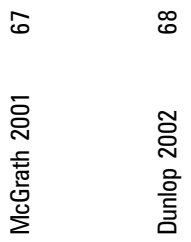

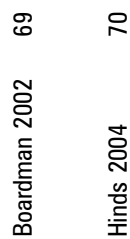

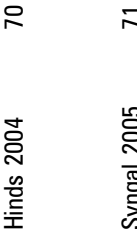

$=\approx N$

吾

总

क्षे

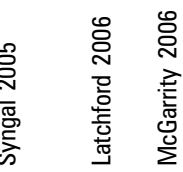

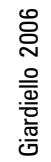

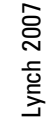




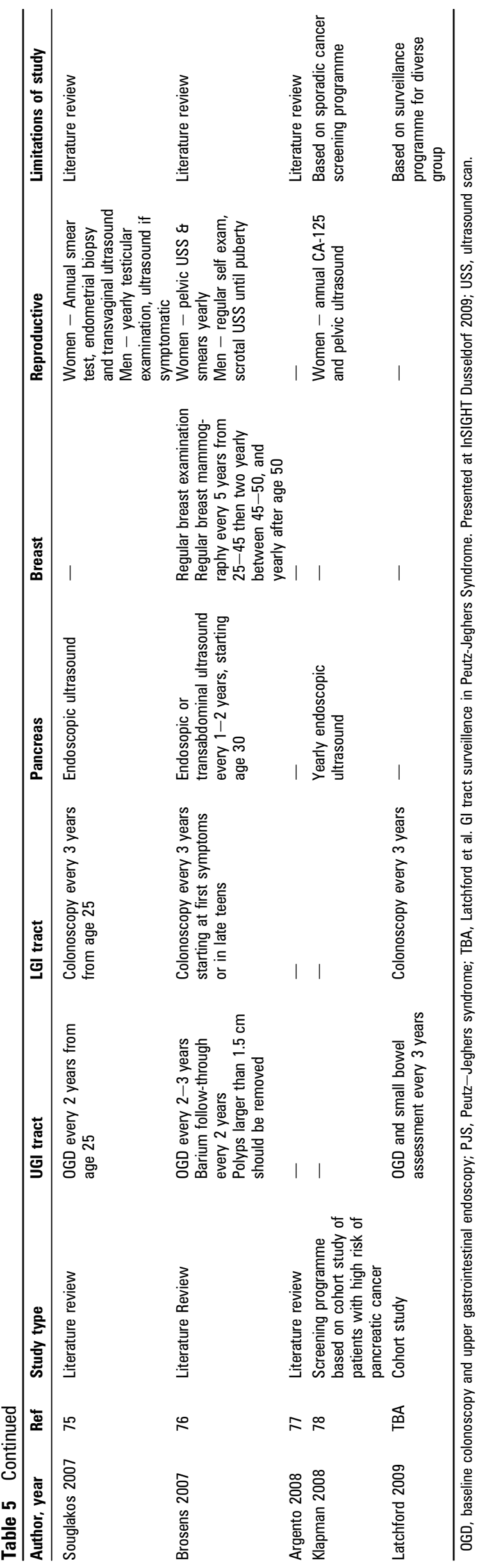

$31-54 \%$ at age 60 years, ${ }^{41}{ }^{53}$ usually ductal, sometimes lobular with a mean age at diagnosis of 37 years (19-48), is significant.

Breast cancer screening can be carried out via a variety of methods including digital x-ray mammography, MR mammography, ultrasound and self-examination. Radiological techniques confer greater sensitivity than self-examination but the radiation burden of repeated x-ray mammography is significant. In addition, the sensitivity of mammography in younger patients with dense breast tissue is reduced. In diagnostic use, ultrasound and MR mammography both increase diagnostic accuracy in a younger patient group with dense breast tissue compared to $\mathrm{x}$ ray mammography. ${ }^{85}$ However, MRI mammography is significantly superior to ultrasound in screening. A model developed to assess cost effectiveness of breast cancer screening with contrast-enhanced MRI in patients with germline BRCA1 and 2 mutations demonstrated that screening with MRI, alone or in combination with x-ray mammography, is cost effective by current standards compared with x-ray mammography alone. ${ }^{86}$

Although no breast screening techniques have been evaluated specifically in patients with PJS, due to the fact that the risk is approaching that of patients with $B R C A$ mutations, it would seem logical that the breast surveillance programme recommended for BRCA mutation and other high risk patients be utilised in PJS ${ }^{87}$; namely annual MRI from age 25 years. These guidelines recommend mammography in addition, because of the high incidence of ductal carcinoma in situ (DCIS) associated with BRCA mutations. There is currently no evidence of increased incidence of DCIS in PJS.

MR mammography may not currently be widely available. It is also more expensive than mammography and may not be tolerated by some individuals. In this setting it may be reasonable to offer supplemental ultrasound, especially in those with dense breast tissue, although it is not recommended as a screening modality.

Conclusion: Annual MRI/US should start at age 25-30 years, with $x$-ray mammography being substituted after the age of 50. (Level of evidence: IV, Grade of recommendation: C)

Question: Is pancreatic cancer surveillance useful in PJS?

The degree to which pancreatic cancer risk is elevated is unclear. Hearle et $a l^{41}$ observed a cumulative risk of $7 \%$ at age 60 , which is at markedly less than $36 \%$ by 64 years observed by Giardiello et al. ${ }^{53}$

Screening for pancreatic cancer is particularly difficult and to date there are no firm data that demonstrate clear benefit even in the setting of a higher risk of development of pancreatic cancer (eg, hereditary pancreatitis). The sequence of the development of pancreatic cancer is thought to be similar to that of the adenoma-carcinoma sequence in colorectal cancer. Initially, a pancreatic intraepithelial neoplasia (PanIN) lesion (elongated mucin-producing cells with little neoplasia) develops, leading through to PanIN-lll lesions (carcinoma in situ). Although this model of progression is widely accepted it has not been fully validated and the natural history of PanIN, in terms of time to progression to cancer, has not been established. In addition early lesions are not radiologically detectable until the development of associated secondary changes such as fibrosis and retention cysts. ${ }^{72}$

Suggested screening regimes have included endoluminal ultrasonography (sensitive), CT (not sensitive for detecting small lesions especially PanIN) and endoscopic cholangiopancreatography (ERCP), with molecular analysis of pancreatic secretions, ${ }^{88}$ specifically for $\mathrm{k}-R A S$ mutations (not specific for cancer); p16/INK4A and p53 mutations (more specific) and methylation analysis of the $p 16 / I N K 4 A$ promoter (60\% sensitivity, 90\% specificity). However, in order to harvest 
these pancreatic secretions, ERCP must be used. The complications of ERCP are pancreatitis (6.7\% incidence), which is severe in $0.3 \%$, and a mortality rate of $0.03 \%$ post-procedure. Magnetic resonance cholangiopancreatography (MCRP) is a possible alternative to the other modalities, but there is no evidence for its routine use. It has been estimated that implementing a surveillance programme in PJS would cost in excess of US\$ 350000 per life saved, assuming that all cases of pancreatic cancer diagnosed during the programme survived. ${ }^{72}$

Conclusion: Routine surveillance for pancreatic cancer in PJS using current methods is not proven to be of benefit and is not cost effective. It should only be performed in the setting of a clinical research study. (Evidence level: III, Grade of recommendation: B)

Question: Should surveillance for genital tract malignancies be performed in PJS?

The increase in ovarian tumour risk is mainly not for epithelial ovarian cancer but for SCTAT, which can occur in very young children ( 2 and 4 years of age reported in the study by Lim et $a l^{54}$ ) although the main risk appears to be in the fourth and fifth decades of life. Giardiello et a ${ }^{53}$ reported a $21 \%$ lifetime risk of ovarian tumours, a risk of cervical cancer of $9 \%$ by 64 years (mean age at diagnosis 34 years) and 10\% of uterine cancer. The risks observed by Hearle and colleagues are lower. ${ }^{41}$ They observed nine gynaecological cancers (two uterine, two ovarian and five cervical), with a risk of $1 \%$ at age 30 years, rising to $18 \%$ at age 60 years.

Ovarian cancer screening is based on CA-125 levels and transvaginal ultrasound scanning, and has been suggested at 6-12 monthly intervals in patients with PJS. ${ }^{77}$ However, as epithelial ovarian cancer is not a specific risk, and there are no data on this type of surveillance in PJS, this recommendation is not supported by evidence. Furthermore, initial findings from the UKCTOCS have recently been reported, assessing multimodal screening (ultrasound and Ca-125) for ovarian cancer in a postmenopausal cohort. ${ }^{89}$ The positive predictive value (PPV) was poor: $43 \%$ for multimodal screening and only $5 \%$ for ultrasound. In addition an effect on survival using multimodal screening has not yet been demonstrated. The poor PPV observed reflects the high prevalence of benign adnexal abnormalities. In PJS, the ovarian tumours are SCTAT, and there is no clear evidence about the effectiveness of any screening modality for this type of tumour. In a younger cohort of PJS patients, it would be a concern that there would be a higher prevalence of benign pathology detected by screening and unnecessary surgical intervention might be performed as a result.

Surveillance for endometrial cancer could be similar to that of Lynch syndrome patients, with a 12-month interval being recommended, from 35 years of age. Endometrial pipelle biopsy sampling and trans-vaginal ultrasound are the recommended screening modalities. ${ }^{90}$ However, the value of surveillance for endometrial cancer in Lynch syndrome is unknown. ${ }^{1}$ Given that most cases of sporadic endometrial cancer are detected at an early stage and the risk of endometrial cancer in PJS is much lower than in Lynch syndrome, it would be reasonable to argue that endometrial surveillance is unnecessary and certainly has no evidence to support its use.

Population cervical screening is widely practised and has been shown to be effective in the reduction of cervical cancer and associated mortality ${ }^{91} 92$ There are no studies that have specifically addressed any means of surveillance for cervical cancer in patients with PJS. It has been recommended on expert opinion that patients with PJS undergo cervical smears as per population screening programme but with a high index of suspicion for adenoma malignum. This would mean a smear every $2-3$ years using the new technique of liquid-based cytology (LBC) ${ }^{91}$ from age 21 to 25 years.

Testicular cancer surveillance is recommended on the basis of expert opinion only. In a literature review all cancers detected were Sertoli cell tumours and occurred at an average age of 9 years. ${ }^{53}$ Annual testicular examination ${ }^{47} 93$ is recommended with ultrasound scanning reserved for patients where an abnormality is found or precocious puberty develops.

Conclusion: There is no evidence to support routine screening for genital tract malignancies in PJS. However, expert opinion advocates regular screening consisting of 2-3 yearly cervical smears using liquidbased cytology (LBC) from age 25 years, testicular examination and testicular ultrasound in patients where an abnormality is detected at examination. Routine surveillance for endometrial and ovarian cancers is not recommended. (Evidence level: IV, Grade of recommendation: C)

Question: Are there any other malignant tumours that should be part of a PJS surveillance programme?

Thyroid cancer may be slightly increased in PJS, and has been reported at a young age ( 30 years $)^{48}$ but screening for thyroid cancer is not validated although clinical thyroid examination could be included in regular clinical examinations of PJS patients. Lung cancer is also increased, with a young age at diagnosis (mean age at diagnosis 49 years), ${ }^{48}$ but screening for this has not been advocated.

Conclusion: There is no evidence for screening of other malignancies in PJS (Evidence level: IV, Grade of recommendation: C)

\section{Therapy}

Few options exist for the therapeutic management of PJS. Surgical strategies are common with dealing with the sequelae of PJS such as small bowel intussusception due to hamartomatous polyps or resection of neoplastic lesions.

Question: Is endoscopic polypectomy of benefit?

Endoscopic polypectomy is recommended at upper GI endoscopy and colonoscopy to reduce cancer risk 9394 based on data obtained from patients with a sporadic adenomatous polyp. As the malignant potential of polyps in PJS is unknown, it is not clear if endoscopic polypectomy alters cancers risk. Latchford et al ${ }^{79}$ found only six cases of atypia or dysplasia in over 1000 PJS polyps; there were no polyps with adenomatous foci or malignant change. ${ }^{79}$ The rarity of dysplasia and neoplasia argues against a hamartoma-adenoma-carcinoma pathway and therefore it is likely that polypectomy does not influence cancer risk.

The recent development of the double balloon enteroscope ${ }^{95}$ and the capsule endoscopy device ${ }^{95}$ have allowed direct visualisation of the small bowel, and in the case of the double balloon enteroscope, resection of polyps via a standard snare polypectomy.

Intra-operative enteroscopy (IOE) has been also recommended ${ }^{6796}$ in any patient with PJS undergoing laparotomy, as careful endoscopy via an enterotomy in the small bowel allows identification and removal of polyps found in the small bowel, thus avoiding multiple enterotomies and the risk of short bowel syndrome associated with resection. This technique allows greater sensitivity in polyp detection than palpation and transillumination (38\% of polyps identified at IOE were not detected by these methods, ${ }^{97}$ and removal of all detected polyps ("clean sweep') reduced the re-laparotomy rate significantly. ${ }^{98}$

It is likely that the main benefit of polypectomy is to prevent polyp-related complications rather than reduce cancer risk. Prevention of anaemia and bleeding is difficult to quantify but certainly IOE has been shown to reduce the risk of further operative polypectomy in the future. ${ }^{99}$

Conclusion: Endoscopic polypectomy reduces polyp-related complications and risk of future operative polypectomy. If a laparotomy 
is performed on a patient with PJS, either as an emergency for obstruction/intussusception, or electively for the removal of large or symptomatic polyps which cannot be removed endoscopically, IOE and 'clean sweep' polypectomy should be undertaken (Evidence level: IIb, Grade of recommendation: B)

Question: Does pharmacological prophylaxis exist for PJS patients?

Lack of LKB1 kinase in PJS and many sporadic cancers drives cell growth and proliferation by inappropriate activation of mTOR protein kinase cascade. Recent animal-based studies have focused upon inhibitors of the mTOR pathway, specifically rapamycin. ${ }^{100} \mathrm{Lkb} 1 \pm$ mice were treated with rapamycin $2 \mathrm{mg} /$ $\mathrm{kg} /$ day and killed mice were examined for polyp burden. It was found that tumour burden decreased significantly in the treatment group, suggesting that rapamycin may have potential as a therapeutic agent in patients with STK11 mutations. There is a clinical trial (NCT00811590) under way in PJS patients of everolimus (RAD001), which inhibits one of the complexes of mTOR, mTORC1 but does not inhibit mTORC2. Some companies also are trialling PI3-kinase, AKT and PDK1 inhibitors, upstream regulators of $\mathrm{mTOR}$.

The role of the pro-inflammatory cyclooxygenase pathway in the pathogenesis of PJS polyps has been studied in a mouse model by Udd et al. ${ }^{101}$ LKB1 \pm mice were treated with $1500 \mathrm{ppm}$ of celecoxib, a selective COX2 inhibitor. These mice were found to have a $54 \%$ reduction in polyp burden. A very small clinical trial within this study was carried out in six patients with documented STK11 mutations who were treated with $400 \mathrm{mg}$ of celecoxib daily for 6 months. In two patients gastric polyp burden was reduced after treatment with celecoxib.

Metformin has been identified as a potential agent that could slow the development of neoplasia in PJS. Using a PTEN-deficient mouse model, Huang et a ${ }^{102}$ demonstrated that activation of the LKB1-AMPK pathway by metformin, phenformin or A769662 significantly slowed tumour onset and identified the potential of metformin in polyposis syndromes associated with the dysregulation of LKB1 and PTEN.

Large cell calcified Sertoli cell tumours (LCST) can lead to gynaecomastia, which has been hypothesised to be due to an alteration in inhibin regulation. A small study examined the use of anastrozole, an aromatase inhibitor used for the treatment of breast carcinoma ${ }^{61}$ to inhibit the clinical features of LCST and found that oestradiol and inhibin levels decreased, suggesting that it may have a role in this condition. However, as these tumours have a malignant potential, bilateral orchidectomy is still recommended as a curative procedure. ${ }^{67}$

Conclusion: There are a number of potentially promising agents for reduction of polyp burden in PJS; however, none of these are in routine clinical use (Evidence level: IIb, Grade of recommendation: B)

Question: Is there any treatment to ameliorate the mucocutaneous pigmentation seen in PJS?

Although the mucocutaneous pigmentation seen in PJS may fade with age, it can be disfiguring and cause psychological stress. The use of filtered intense pulse light (IPL) with a $590 \mathrm{~nm}$ cut-off filter was reported in a single case whereby it led to a rapid improvement in the cosmetic appearance of the lesions. ${ }^{103}$ Similar improvements have also been described with Q-switched ruby laser ${ }^{104} 105$ and $\mathrm{CO}_{2}$-based lasers. ${ }^{106}$

Conclusion: Although there have been reports of success with intense pulsed light and laser therapy, their use cannot be supported in routine clinical practice. Its use should be reserved for cases with significant psychological morbidity related to pigmentation (Evidence level: IV, Grade of recommendation: C)

\section{DISCUSSION AND CONCLUSIONS}

Peutz-Jeghers syndrome is a clinically diverse disease entity, with multiple neoplastic manifestations and a very high lifetime risk of developing malignancy. The current evidence for surveillance guidelines is weak due to the relative rarity of PJS and the lack of data addressing effectiveness and outcomes from surveillance in PJS.

Current surveillance guidelines are highly intensive. Several of the surveillance modalities presented here are invasive and the frequency at which they are carried out presents a significant burden for the PJS patient. Surveillance has two purposes in PJS patients: first, to reduce the polyp burden and the likelihood of polyp related complications, particularly intussusception, in the young PJS patient; and, second, cancer surveillance in the older PJS patient. We have attempted to reflect this in our guidelines. The main aim of surveillance in childhood should be reducing the risk of intussusception. As such we have recommended that endoscopic examination is less frequent in this age group compared to adult patients, where the main aim is detecting cancer at an early stage. Recommendations on surveillance, therapy and clinical management are summarised in boxes 1 and 2 .

The lack of understanding regarding cancer development in PJS makes the generation of surveillance guidelines problematic, when one of the main aims is cancer detection/prevention. Studies to clarify cancer development and the malignant potential of PJS polyps are required and may have a significant impact on our current recommendations.

There is little research currently about potential biomarkers for the identification of early neoplasia, with the exception of colorectal (faecal occult blood, faecal k-RAS) and pancreatic lesions ( $\mathrm{k}-R A S$ in pancreatic secretions), but these methods lack sensitivity and specificity and have only been applied previously to sporadic cancer. Radiological screening shows promise in certain tumour types; however, tumours such as ovarian carcinoma are difficult to diagnose effectively by conventional

Box 1 Summary of recommendations for surveillance and follow-up

General

Annual full blood count (FBC), Liver function testing (LFT)

Annual clinical examination

Genital tract

Annual examination and testicular examination from birth until 12 years

Testicular ultrasound if abnormalities detected at examination

Cervical smear with LBC three yearly from age 25 years

Gastrointestinal

Baseline $0 \mathrm{GD} /$ colonoscopy age 8

Polyps detected, continue three yearly until 50 years

No polyps detected, repeat age 18 years, then three yearly until 50 years

Colonoscopy $1-2$ yearly after age 50 years

VCE every 3 years from age 8 years

Breast

Monthly self examination from age 18 years

Annual breast MRI from age 25-50, thereafter annual mammographyLBC, liquid-based cytology; MRI, magnetic resonance imaging; $\mathrm{OGD}$, baseline colonoscopy and upper gastrointestinal endoscopy; VCE, video capsule endoscopy. 
Box 2 Summary of guidelines and grading of recommendation

1. Gastrointestinal surveillance using colonoscopy, upper GI endoscopy and video capsule endoscopy should be performed....GRADE C

2. Magnetic resonance imaging mammography is recommended....GRADE C

3. Pancreatic surveillance is not recommended....GRADE B

4. Testicular examination and ultrasound is recommended... GRADE C

5. Cervical smears are recommended....GRADE C

6. Ovarian and uterine surveillance are not recommended... GRADE C

7. An intraoperative enteroscopy should be performed on patients with Peutz-Jeghers syndrome who are undergoing laparotomy....GRADE B

8. No pharmacological prophylaxis can be recommended for routine use....GRADE B

9. Intense pulsed light and laser therapy, should be reserved for cases with significant psychological morbidity related to pigmentation....GRADE C

radiological methods until they have progressed beyond an early, pre-invasive stage.

Endoscopic polypectomy via upper GI endoscopy, colonoscopy and double-balloon enteroscopy has demonstrated its utility in reducing the need for future operative polypectomy from the small bowel. Double-balloon enteroscopy, however, can be a traumatic procedure and its use currently is limited to therapy rather than diagnosis. The development of capsule endoscopy has enhanced the diagnostic armamentarium available to the clinician and allows more thorough and regular surveillance of the small bowel for polyposis.

The mTOR pathway shows significant promise for modulation or limitation of progression of PJS polyps; however, clinical trials in this area are at a very early stage and involve some agents, such as everolimus/sirolimus that carry a risk of significant systemic toxicity. Intervention in the COX2 pathway also shows promise, although a very limited study has examined the role of celecoxib which has now been associated with increases in cardiovascular disease risk and therefore its long term use may not be suitable in this group.

In conclusion, guidelines for PJS are largely formed via consensus rather than a robust evidence base. Therapeutic interventions and surveillance modalities are expanding, but assessment of these is challenging given the rarity of the condition.

\section{Author affiliations:}

'Department of Clinical Genetics, St George's Hospital, London, UK

${ }^{2}$ Department of Gastroenterology, Derriford Hospital, University of Plymouth, Devon, UK

${ }^{3}$ Department of Gastroenterology and Hepatology, Leiden University Medical Centre, Leiden, The Netherlands

${ }^{4}$ Department of Surgery, St Josefs Hospital Bochum-Linden (Helios), Bochum, Germany

${ }^{5}$ Department of Medical Genetics, Hospital Virgen del Camino, Pamplona, Spain

${ }^{6}$ Institute of Human Genetics, University of Bonn, Germany

${ }^{7}$ Department of Surgery, Hospital Tumori, Milan, Italy

${ }^{8}$ Genetic Counselling Unit, Prevention and Cancer Control Department, Catalan Institute of Oncology, Barcelona, Spain

${ }^{9}$ Danish Polyposis Registry, Department of Surgery, Hvidovre University Hospital, Hvidovre, Denmark

${ }^{10}$ Institute of Human Genetics, Newcastle-upon-Tyne, UK
${ }^{11}$ Institute Catala D'Oncologia, Barcelona, Spain

${ }^{12}$ Laboratoire d'Oncogenetique, Groupe Hospitalier Pitié-Salpêtre, Paris

${ }^{13}$ Section of Inherited Cancer, Department of Medical Genetics, Rikshospitalet-Radium

Hospitalet Medical Centre, Oslo, Norway

${ }^{14}$ Departments of Human \& Clinical Genetics, Leiden University Medical Centre, The

Netherlands

${ }^{15}$ Department of Surgery, Helsinki University Central Hospital, Helsinki, Finland

${ }^{16}$ Department of Surgery, Jyvaskyla Central Hospital, Jyvaskyla, Finland

${ }^{17}$ Department of Gastroenterology and Hepatology, Radboud University Medical

Centre, Nijmegen, The Netherlands

${ }^{18}$ Department of Digestive Surgery, Hospital Saint-Antoine, University Pierre et Marie,

Paris, France

${ }^{19}$ The Polyposis Registry, St Mark's Hospital, Harrow, Middlesex, UK

${ }^{20}$ Department of Internal Medicine, University Hospital, Modena, Italy

${ }^{21}$ Institute of Medical Genetics, School of Medicine, Cardiff University, UK

${ }^{22}$ Department of Medical Genetics, Ullevål University Hospital, Oslo, Norway

${ }^{23}$ Digestive Oncology Unit, Department of Internal Medicine, University Hospital

Gasthuisberg, Leuven, Belgium

${ }^{24}$ CRUK, Family Cancer Group, St Mark's Hospital, Harrow, Middlesex, UK

\section{Competing interests None.}

Contributors A Beggs and A Latchford contributed equally to the preparation of this manuscript.

Provenance and peer review Not commissioned; externally peer reviewed.

\section{REFERENCES}

1. Vasen HF, Moslein G, Alonso A, et al. Guidelines for the clinical management of Lynch syndrome (hereditary non-polyposis cancer). J Med Genet 2007:44:353-62.

2. Vasen HF, Moslein G, Alonso A, et al. Guidelines for the clinical management of familial adenomatous polyposis (FAP). Gut 2008;57:704-13.

3. Connor JT. Aesculapian Society of London. Lancet 1895:2:1169.

4. Hutchinson J. Pigmentation of lips and mouth. Archives of Surgery 1896;7:290-1.

5. Bruwer A, Bargen JA, Kierland RR. Surface pigmentation and generalized intestinal polyposis; (Peutz-Jeghers syndrome). Proc Staff Meet Mayo Clin 1954;29:168-71.

6. Peutz J. Very remarkable case of familial polyposis of mucous membrane of intestinal tract and nasopharynx accompanied by peculiar pigmentation of skin and mucous membrane. Nederl Maandschr Geneesk 1921;10:134-46.

7. Jeghers $\mathbf{H}, \mathrm{Mc} \mathrm{KV}$, Katz KH. Generalized intestinal polyposis and melanin spots of the oral mucosa, lips and digits; a syndrome of diagnostic significance. $N$ Engl $J$ Med 1949;241:1031-6.

8. Jeghers $\mathbf{H}, \mathbf{M c} \mathrm{KV}$, Katz KH. Generalized intestinal polyposis and melanin spots of the oral mucosa, lips and digits; a syndrome of diagnostic significance. $N$ Engl J Med 1949;241:993, illust; passim.

9. Giardiello FM, Trimbath JD. Peutz-Jeghers syndrome and management recommendations. Clin Gastroenterol Hepatol 2006:4:408-15.

10. McCarthy PM, Piehler JM, Schaff HV, et al. The significance of multiple, recurrent and "complex" cardiac myxomas. J Thorac Cardiovasc Surg 1986;91:389-96.

11. Jass JR, Williams CB, Bussey HJ, et al. Juvenile polyposis-a precancerous condition. Histopathology 1988;13:619-30.

12. de Leng WW, Jansen $M$, Keller JJ, et al. Peutz-Jeghers syndrome polyps are polyclonal with expanded progenitor cell compartment. Gut 2007;56:1475-6.

13. Shepherd NA, Bussey HJ, Jass JR. Epithelial misplacement in Peutz-Jeghers polyps. A diagnostic pitfall. Am J Surg Pathol 1987;11:743-9.

14. Utsunomiya J, Gocho H, Miyanaga T, et al. Peutz-Jeghers syndrome: its natural course and management. Johns Hopkins Med J 1975;136:71-82.

15. Vogel T, Schumacher V, Saleh A, et al. Extraintestinal polyps in Peutz-Jeghers syndrome: presentation of four cases and review of the literature. Deutsche Peutz-Jeghers-Studiengruppe. Int J Colorectal Dis 2000;15:118-23.

16. Aaltonen LA. Hereditary intestinal cancer. Semin Cancer Biol 2000;10:289-98.

17. Aretz S, Stienen D, Uhlhaas S, et al. High proportion of large genomic STK11 deletions in Peutz-Jeghers syndrome. Hum Mutat 2005;26:513-19.

18. Amos CI, Bali D, Thiel TJ, et al. Fine mapping of a genetic locus for Peutz-Jeghers syndrome on chromosome 19p. Cancer Res 1997;57:3653-6.

19. Mehenni H, Blouin JL, Radhakrishna U, et al. Peutz-Jeghers syndrome: confirmation of linkage to chromosome 19p13.3 and identification of a potential second locus, on 19q13.4. Am J Hum Genet 1997;61:1327-34.

20. Hemminki A, Markie D, Tomlinson I, et al. A serine/threonine kinase gene defective in Peutz-Jeghers syndrome. Nature 1998;391:184-7.

21. Jenne DE, Reimann $\mathrm{H}, \mathrm{Nezu} J$, et al. Peutz-Jeghers syndrome is caused by mutations in a novel serine threonine kinase. Nat Genet 1998;18:38-43.

22. Volikos E, Robinson J, Aittomaki K, et al. LKB1 exonic and whole gene deletions are a common cause of Peutz-Jeghers syndrome. J Med Genet 2006;43:e18.

23. de Leng WW, Jansen $M$, Carvalho $R$, et al. Genetic defects underlying Peutz-Jeghers syndrome (PJS) and exclusion of the polarity-associated MARK/ Par1 gene family as potential PJS candidates. Clin Genet 2007;72:568-73.

24. Marignani PA. LKB1, the multitasking tumour suppressor kinase. J Clin Pathol 2005;58:15-19.

25. Tiainen M, Vaahtomeri K, Ylikorkala A, et al. Growth arrest by the LKB1 tumor suppressor: induction of p21(WAF1/CIP1). Hum Mol Genet 2002;11:1497-504. 
26. Tiainen M, Ylikorkala A, Makela TP. Growth suppression by Lkb1 is mediated by a G(1) cell cycle arrest. Proc Natl Acad Sci U S A 1999;96:9248-51.

27. Karuman $\mathbf{P}$, Gozani $\mathbf{0}$, Odze RD, et al. The Peutz-Jegher gene product LKB1 is a mediator of p53-dependent cell death. Mol Cell 2001;7:1307-19.

28. Morton DG, Roos JM, Kemphues KJ. par-4, a gene required for cytoplasmic localization and determination of specific cell types in Caenorhabditis elegans embryogenesis. Genetics 1992;130:771-90.

29. Lin-Marq N, Borel C, Antonarakis SE. Peutz-Jeghers LKB1 mutants fail to activate GSK-3beta, preventing it from inhibiting Wnt signaling. Mol Genet Genomics 2005; 273:184-96.

30. Alessi DR, Sakamoto K, Bayascas JR. LKB1-dependent signaling pathways. Annu Rev Biochem 2006;75:137-63.

31. Corradetti MN, Inoki K, Bardeesy N, et al. Regulation of the TSC pathway by LKB1: evidence of a molecular link between tuberous sclerosis complex and Peutz-Jeghers syndrome. Genes Dev 2004;18:1533-8.

32. McGarrity TJ, Peiffer LP, Amos Cl, et al. Overexpression of cyclooxygenase 2 in hamartomatous polyps of Peutz-Jeghers syndrome. Am J Gastroenterol 2003;98:671-8.

33. Tomlinson IP, Olschwang $\mathrm{S}$, Abelovitch D, et al. Testing candidate loci on chromosomes 1 and 6 for genetic linkage to Peutz-Jeghers' disease. Ann Hum Genet 1996;60:377-84.

34. Buchet-Poyau K, Mehenni $\mathrm{H}$, Radhakrishna U, et al. Search for the second Peutz-Jeghers syndrome locus: exclusion of the STK13, PRKCG, KLK10, and PSCD2 genes on chromosome 19 and the STK11IP gene on chromosome 2. Cytogenet Genome Res 2002; 97:171-8.

35. Mehenni H, Gehrig C, Nezu J, et al. Loss of LKB1 kinase activity in Peutz-Jeghers syndrome, and evidence for allelic and locus heterogeneity. Am J Hum Genet 1998:63:1641-50.

36. Alhopuro P, Phichith D, Tuupanen $\mathrm{S}$, et al. Unregulated smooth-muscle myosin in human intestinal neoplasia. Proc Natl Acad Sci U S A 2008;105:5513-18.

37. Amos Cl, Keitheri-Cheteri MB, Sabripour M, et al. Genotype-phenotype correlations in Peutz-Jeghers syndrome. J Med Genet 2004;41:327-33.

38. Schumacher V, Vogel T, Leube B, et al. STK11 genotyping and cancer risk in Peutz-Jeghers syndrome. J Med Genet 2005:42:428-35

39. Mehenni H, Resta N, Guanti G, et al. Molecular and clinical characteristics in 46 families affected with Peutz-Jeghers syndrome. Dig Dis Sci 2007;52:1924-33.

40. Velez A, Gaitan MH, Marquez JR, et al. Two novel LKB1 mutations in Colombian Peutz-Jeghers syndrome patients. Clin Genet 2009;75:304-6.

41. Hearle N, Schumacher V, Menko FH, et al. Frequency and spectrum of cancers in the Peutz-Jeghers syndrome. Clin Cancer Res 2006;12:3209-15.

42. Bosman FT. The hamartoma-adenoma-carcinoma sequence. J Pathol 1999;188:1-2.

43. Bouraoui S, Azouz $\mathrm{H}$, Kechrid $\mathrm{H}$, et al. [Peutz-Jeghers' syndrome with malignant development in a hamartomatous polyp: report of one case and review of the literature] (In French). Gastroenterol Clin Biol 2008;32:250-4.

44. Jansen M, de Leng WW, Baas AF, et al. Mucosal prolapse in the pathogenesis of Peutz-Jeghers polyposis. Gut 2006:55:1-5.

45. Su GH, Hruban RH, Bansal RK, et al. Germline and somatic mutations of the STK11/ LKB1 Peutz-Jeghers gene in pancreatic and biliary cancers. Am J Pathol 1999:154:1835-40.

46. Giardiello FM, Welsh SB, Hamilton SR, et al. Increased risk of cancer in the Peutz-Jeghers syndrome. N Engl J Med 1987;316:1511-14

47. Spigelman AD, Murday V, Phillips RK. Cancer and the Peutz-Jeghers syndrome. Gut 1989;30:1588-90.

48. Boardman LA, Thibodeau SN, Schaid DJ, et al. Increased risk for cancer in patients with the Peutz-Jeghers syndrome. Ann Intern Med 1998;128:896-9.

49. Linos DA, Dozois RR, Dahlin DC, et al. Does Peutz-Jeghers syndrome predispose to gastrointestinal malignancy? a later look. Arch Surg 1981;116:1182-4.

50. Choi HS, Park YJ, Youk EG, et al. Clinical characteristics of Peutz-Jeghers syndrome in Korean polyposis patients. Int J Colorectal Dis 2000;15:35-8.

51. Hizawa K, lida M, Matsumoto T, et al. Cancer in Peutz-Jeghers syndrome. Cancer 1993;72:2777-81

52. Laughlin EH. Benign and malignant neoplasms in a family with Peutz-Jeghers syndrome: study of three generations. South Med J 1991;84:1205-9.

53. Giardiello FM, Brensinger JD, Tersmette AC, et al. Very high risk of cancer in familial Peutz-Jeghers syndrome. Gastroenterology 2000;119:1447-53.

54. Lim W, Olschwang S, Keller JJ, et al. Relative frequency and morphology of cancers in STK11 mutation carriers. Gastroenterology 2004;126:1788-94.

55. Mehenni H, Resta N, Park JG, et al. Cancer risks in LKB1 germline mutation carriers. Gut 2006;55:984-90.

56. Young RH, Welch WR, Dickersin GR, et al. Ovarian sex cord tumor with annular tubules: review of 74 cases including 27 with Peutz-Jeghers syndrome and four with adenoma malignum of the cervix. Cancer 1982;50:1384-402.

57. Song SH, Lee JK, Saw HS, et al. Peutz-Jeghers Syndrome with multiple genital tract tumors and breast cancer: a case report with a review of literatures. J Korean Med Sci 2006;21:752-7.

58. Lele SM, Sawh RN, Zaharopoulos P, et al. Malignant ovarian sex cord tumor with annular tubules in a patient with Peutz-Jeghers syndrome: a case report. Mod Pathol 2000;13:466-70

59. Srivatsa PJ, Keeney GL, Podratz KC. Disseminated cervical adenoma malignum and bilateral ovarian sex cord tumors with annular tubules associated with Peutz-Jeghers syndrome. Gynecol Oncol 1994;53:256-64.
60. Kilic-0kman T, Yardim T, Gucer F, et al. Breast cancer, ovarian gonadoblastoma and cervical cancer in a patient with Peutz-Jeghers Syndrome. Arch Gynecol Obstet 2008; 278:75-7.

61. Lefevre $\mathbf{H}$, Bouvattier $\mathrm{C}$, Lahlou $\mathrm{N}$, et al. Prepubertal gynecomastia in Peutz-Jeghers syndrome: incomplete penetrance in a familial case and management with an aromatase inhibitor. Eur J Endocrinol 2006;154:221-7.

62. Dozois RR, Kempers RD, Dahlin DC, et al. Ovarian tumors associated with the Peutz-Jeghers syndrome. Ann Surg 1970;172:233-8.

63. von Herbay A, Arens N, Friedl W, et al. Bronchioloalveolar carcinoma: a new cancer in Peutz-Jeghers syndrome. Lung Cancer 2005;47:283-8.

64. Eccles M, Clapp Z, Grimshaw J, et al. North of England evidence based guidelines development project: methods of guideline development. BMJ 1996;312:760-2.

65. Hemminki A. The molecular basis and clinical aspects of Peutz-Jeghers syndrome. Cell Mol Life Sci 1999;55:735-50.

66. Burt RW. Colon cancer screening. Gastroenterology 2000:119:837-53.

67. McGrath DR, Spigelman AD. Preventive measures in Peutz-Jeghers syndrome. Fam Cancer 2001:1:121-5

68. Dunlop MG. Guidance on gastrointestinal surveillance for hereditary non-polyposis colorectal cancer, familial adenomatous polypolis, juvenile polyposis, and Peutz-Jeghers syndrome. Gut 2002;51 (Suppl 5):V21-7.

69. Boardman LA. Heritable colorectal cancer syndromes: recognition and preventive management. Gastroenterol Clin North Am 2002;31:1107-31.

70. Hinds R, Philp C, Hyer W, et al. Complications of childhood Peutz-Jeghers syndrome: implications for pediatric screening. J Pediatr Gastroenterol Nutr 2004;39:219-20.

71. Syngal S, Bandipalliam P, Boland CR. Surveillance of patients at high risk for colorectal cancer. Med Clin North Am 2005:89:61-84, vii-viii.

72. Latchford A, Greenhalf W, Vitone LJ, et al. Peutz-Jeghers syndrome and screening for pancreatic cancer. Br J Surg 2006:93:1446-55.

73. McGarrity TJ, Amos C. Peutz-Jeghers syndrome: clinicopathology and molecular alterations. Cell Mol Life Sci 2006;63:2135-44.

74. Lynch HT, Lynch JF, Lynch PM, et al. Hereditary colorectal cancer syndromes: molecular genetics, genetic counseling, diagnosis and management. Fam Cancer 2008; 7:27-39.

75. Souglakos J. Genetic alterations in sporadic and hereditary colorectal cancer: implementations for screening and follow-up. Dig Dis 2007;25:9-19.

76. Brosens LA, van Hattem WA, Jansen M, et al. Gastrointestinal polyposis syndromes. Curr Mol Med 2007;7:29-46.

77. Argento M, Hoffman P, Gauchez AS. Ovarian cancer detection and treatment: current situation and future prospects. Anticancer Res 2008:28:3135-8.

78. Klapman J, Malafa MP. Early detection of pancreatic cancer: why, who, and how to screen. Cancer Control 2008;15:280-7.

79. Latchford A, et al. Gl tract surveillence in Peutz-Jeghers Syndrome. Presented at InSIGHT Dusseldorf 2009

80. Brown G, Fraser C, Schofield G, et al. Video capsule endoscopy in Peutz-jeghers syndrome: a blinded comparison with barium follow-through for detection of smallbowel polyps. Endoscopy 2006;38:385-90.

81. Mata A, Llach J, Castells A, et al. A prospective trial comparing wireless capsule endoscopy and barium contrast series for small-bowel surveillance in hereditary GI polyposis syndromes. Gastrointest Endosc 2005;61:721-5.

82. Postgate A, Hyer W, Phillips $R$, et al. Feasibility of video capsule endoscopy in the management of children with Peutz-jeghers syndrome: a blinded comparison with barium enterography for the detection of small bowel polyps. J Pediatr Gastroenterol Nutr 2009:49:417-23.

83. Kurugoglu S, Aksoy H, Kantarci F, et al. Radiological work-up in Peutz-Jeghers syndrome. Pediatr Radiol 2003;33:766-71

84. Caspari R, von Falkenhausen M, Krautmacher $\mathrm{C}$, et al. Comparison of capsule endoscopy and magnetic resonance imaging for the detection of polyps of the smal intestine in patients with familial adenomatous polyposis or with Peutz-Jeghers' syndrome. Endoscopy 2004;36:1054-9.

85. Pediconi F, Catalano C, Roselli A, et al. The challenge of imaging dense breast parenchyma: is magnetic resonance mammography the technique of choice? A comparative study with $x$-ray mammography and whole-breast ultrasound. Invest Radiol 2009; 44:412-21.

86. Taneja C, Edelsberg J, Weycker D, et al. Cost effectiveness of breast cancer screening with contrast-enhanced MRI in high-risk women. J Am Coll Radiol 2009;6:171-9.

87. Saslow D, Boetes C, Burke W, et al. American Cancer Society guidelines for breast screening with MRI as an adjunct to mammography. CA Cancer J Clin 2007;57:75-89.

88. Goggins M. Identifying molecular markers for the early detection of pancreatic neoplasia. Semin Oncol 2007;34:303-10.

89. Menon U, Gentry-Maharaj A, Hallett R, et al. Sensitivity and specificity of multimodal and ultrasound screening for ovarian cancer, and stage distribution of detected cancers: results of the prevalence screen of the UK Collaborative Trial of Ovarian Cancer Screening (UKCTOCS). Lancet Oncol 2009;10:327-40.

90. Schmeler KM, Lu KH. Gynecologic cancers associated with Lynch syndrome/ HNPCC. Clin Transl Oncol 2008;10:313-17.

91. Lancucki L. Cervical screening programme, England: 2004-05. Leeds: Health and Social Care Information Centre, 2005.

92. Peto J, Gilham C, Fletcher 0, et al. The cervical cancer epidemic that screening has prevented in the UK. Lancet 2004;364:249-56.

93. Giardiello FM. Gastrointestinal polyposis syndromes and hereditary non-polyposis colorectal cancer. In: Rustgi AK, ed. Gastrointestinal cancers: biology, diagnosis and therapy. Philadelphia: Lippincott-Raven, 1995:370-1. 
94. Tomlinson IP, Houlston RS. Peutz-Jeghers syndrome. J Med Genet 1997:34:1007-11.

95. Yamamoto H, Kita H. Double-balloon endoscopy: from concept to reality. Gastrointest Endosc Clin N Am 2006;16:347-61.

96. Panos RG, Opelka FG, Nogueras JJ. Peutz-Jeghers syndrome. A call for intraoperative enteroscopy. Am Surg 1990;56:331-3.

97. Spigelman AD, Thomson JP, Phillips RK. Towards decreasing the relaparotomy rate in the Peutz-Jeghers syndrome: the role of peroperative small bowel endoscopy. Br J Surg 1990; 77:301-2.

98. Edwards DP, Khosraviani K, Stafferton R, et al. Long-term results of polyp clearance by intraoperative enteroscopy in the Peutz-Jeghers syndrome. Dis Colon Rectum 2003;46:48-50.

99. Pennazio M, Rossini FP. Small bowel polyps in Peutz-Jeghers syndrome: management by combined push enteroscopy and intraoperative enteroscopy Gastrointest Endosc 2000;51:304-8.
100. Wei C, Amos Cl, Zhang N, et al. Suppression of Peutz-Jeghers polyposis by targeting mammalian target of rapamycin signaling. Clin Cancer Res 2008;14:1167-71.

101. Udd L, Katajisto P, Rossi DJ, et al. Suppression of Peutz-Jeghers polyposis by inhibition of cyclooxygenase-2. Gastroenterology 2004;127:1030-7.

102. Huang $\mathbf{X}$, Wullschleger $\mathbf{S}$, Shpiro N, et al. Important role of the LKB1-AMPK pathway in suppressing tumorigenesis in PTEN-deficient mice. Biochem J 2008;412:211-21.

103. Remington BK, Remington TK. Treatment of facial lentigines in Peutz-Jeghers syndrome with an intense pulsed light source. Dermatol Surg 2002;28:1079-81.

104. Chang CJ, Nelson JS. Q-switched ruby laser treatment of mucocutaneous melanosis associated with Peutz-Jeghers syndrome. Ann Plast Surg 1996;36:394-7.

105. Kato S, Takeyama J, Tanita Y, et al. Ruby laser therapy for labial lentigines in Peutz-Jeghers syndrome. Eur J Pediatr 1998;157:622-4.

106. Benedict LM, Cohen B. Treatment of Peutz-Jeghers lentigines with the carbon dioxide laser. J Dermatol Surg Oncol 1991;17:954-5. 


\section{GUT}

\section{Peutz-Jeghers syndrome: a systematic review and recommendations for management}

A D Beggs, A R Latchford, H F A Vasen, et al.

Gut 2010 59: 975-986

doi: 10.1136/gut.2009.198499

Updated information and services can be found at:

http://gut.bmj.com/content/59/7/975.full.html

These include:

References This article cites 103 articles, 26 of which can be accessed free at: http://gut.bmj.com/content/59/7/975.full.html\#ref-list-1

Article cited in:

http://gut.bmj.com/content/59/7/975.full.html\#related-urls

Email alerting Receive free email alerts when new articles cite this article. Sign up in service the box at the top right corner of the online article.

Notes

To request permissions go to:

http://group.bmj.com/group/rights-licensing/permissions

To order reprints go to:

http://journals.bmj.com/cgi/reprintform

To subscribe to BMJ go to:

http://group.bmj.com/subscribe/ 